\title{
O "ACESSABILIDADE" UM RECURSO PARA INCLUSÃO E PERMANÊNCIA DE ESTUDANTES COM DEFICIÊNCIA NO ENSINO SUPERIOR
}

\author{
Maria Rita Rodrigues Cerqueira ${ }^{1}$, Jaqueline Costa Castilho Moreira ${ }^{2}$ \\ ${ }^{1}$ Universidade Estadual Paulista - UNESP, Departamento de Fisioterapia; Presidente Prudente, SP. ${ }^{2}$ Universidade \\ Estadual Paulista Júlio de Mesquita Filho - UNESP, Departamento de Educação Física, Presidente Prudente, SP. E-mail: \\ fisiomariarita@gmail.com
}

\section{RESUMO}

O objetivo desse trabalho foi apresentar o ACESSAbilidade como um recurso público e acessível capaz de promover ações contínuas que possibilitem a inclusão e a permanência no ensino superior de estudantes público alvo da Educação Especial, sendo desenvolvido na região de Presidente Prudente (SP). Tendo como metodologia uma pesquisa exploratória de abordagem qualitativa, os resultados com o recurso respondeu a questões relativas as características e especificidades das pessoas com deficiência na graduação: como elas aprendem, o que as facilita em termos de tecnologia e adaptações, e a estar aberto a explicitação de suas sugestões pedagógicas para aprimorar a relação didática graduando com os docente; sem constrangimento ou receio. Como conclusões, entende-se que a acessibilidade não é somente o acesso físico aos locais, e sim um conceito mais amplo, que envolve a informação e o estabelecimento de redes comunicacionais.

Palavras-chave: Acessibilidade pedagógica, Educomunicação, Educação inclusiva, Rede social, Cego.

\section{THE "ACCESSABILITY" A RESOURCE FOR THE INCLUSION AND PERMANENCE OF DISABLED STUDENTS IN HIGHER EDUCATION}

\begin{abstract}
The objective of this work was to present ACCESSibility as a public and accessible resource capable of promoting continuous actions that allow the inclusion and permanence in higher education of students targeted by Special Education, being developed in the region of Presidente Prudente (SP). Using an exploratory qualitative approach methodology, the results with the resource answered questions related to the characteristics and specificities of people with disabilities in the undergraduate: how they learn, which facilitates them in terms of technology and adaptations, and be open to explicitation of their pedagogical suggestions to improve the didactic relation graduating with the teachers; without embarrassment or fear. As conclusions, it is understood that accessibility is not only physical access to sites, but a broader concept, which involves the information and establishment of communication networks.
\end{abstract}

Keywords: Pedagogical accessibility, Educommunication, Inclusive education, Social network, Blind. 


\section{INTRODUÇÃO}

As discussões sobre inclusão na educação têm sido enfocadas em muitos estudos e práticas pedagógicas, mas há muito o que aprimorar. No ensino básico, o tema e os desdobramentos das problemáticas que emergem no cotidiano das escolas vêm ocorrendo iniciaram-se anteriormente, sinalizando alguns avanços em termos práticos; divergentemente das ações desta natureza no Ensino Superior, que ainda trilham um percurso.

$\mathrm{Na}$ gênese do acesso ao ensino superior, os cursos de graduação elegiam os possíveis alunos pelo vestibular; como também ao longo do processo de quatro anos ou mais segmentavam desses matriculados, aqueles que conseguiam permanecer e concluir a formação. As estruturas físicas, arquitetônicas, pedagógicas, de gestão de alunos entre outras, até então ofertadas, eram pensadas para atender um público seleto, de caraterísticas que pouco interferiam nos prédios, nas ações didáticas dos professores, no uso de recursos e materiais pedagógicos ou mesmo no trajeto e acomodação desses graduandos aos locais onde as Instituições de Ensino Superior (IES) encontravam-se sediadas.

Embora o número de estudantes com algum tipo de deficiência no ensino superior ainda seja pequeno em cada IES, o direito constitucional ao acesso de todo e qualquer cidadão a Educação de nível superior desestabilizou a realidade posta. Com a inclusão e a implementação da Lei no 13.146 (BRASIL, 2015), além dos questionamentos quanto à amplificação do acesso, vieram às reivindicações de acessibilidade aos prédios e trajetos garantidas pela Justiça, assim como expuseram a premência de instrumentalização dos docentes de nível superior para lidar com a diversidade, além da necessidade de se implantar um projeto político pedagógico voltado a diversidade de graduandos, possibilitando que estas sejam contempladas de maneira favorável e compatível, assim como requisitando a disposição pelas IES de recursos de variadas tecnologias.

Nesse estudo priorizou-se a acessibilidade pedagógica como um dos aspectos que promove transposição de barreiras metodológicas e instrumentais, que se encontram nas dimensões da acessibilidade discutidas em Sassaki $(1996,2009)$, e que remetem também ao o que está prescrito no texto da Lei no 13.146 (BRASIL, 2015).

Na perspectiva de abarcar o fenômeno pelo viés da acessibilidade pedagógica, este estudo apresenta o projeto ACESSAbilidade, um recurso de Educomunicação que estimula simultaneamente a interação social entre os estudantes público alvo da educação especial (pessoas com deficiência, com transtornos globais do desenvolvimento ou com superdotação e/ou altas habilidades) e os sujeitos educacionais (professores, coordenadores, gestores, colegas de curso e outros).

O termo ACESSAbilidade é um neologismo criado a partir da ideia de acessibilidade pedagógica e sua "utilização" de forma habilidosa, ou seja, empregando habilidades técnicas, informacionais, sociais entre outras para "gerir"/"superar" os obstáculos existentes no percurso educacional dos estudantes com relação à acessibilidade pedagógica no ensino superior.

Assim, a concretização da ferramenta ACESSAbilidade perpassa pelos erros e acertos de estruturação de um modelo de comunicação virtual direcionado aos estudantes com deficiência visando sua inclusão e permanência no ensino superior. $O$ intuito foi e permanece de disponibilizar informações, compartilhar ideias, conhecimentos, notícias, recursos pedagógicos direcionados ao atendimento de situações de inclusão específicas, estratégias, reclamações, material de estudo, resolução de situações educacionais, apresentar inovações tecnológicas de domínio público que equiparam oportunidades de estudo; ou de tecnologia assistiva (TA), em um endereço na internet de fácil acesso e com acessibilidade a este público ou a aqueles estudantes que estejam temporária ou permanentemente impossibilitados de prosseguir nos estudos e pessoas interessadas neste tema.

O "link" (ACESSAbilidade, 2016) serve como um ponto de encontro em rede social, no qual podem interagir graduandos nestas condições, os professores e coordenadores diretamente 
envolvidos com eles, outros estudantes parceiros ou colegas, os profissionais ligados ao ensino, a assistência social, a engenharia entre outros.

Vale assinalar que o ACESSAbilidade é uma proposta de interação digital em tecnologia acessível, que pode ser incrementada pelo uso do celular, permitindo a continuidade no tempo e no espaço da troca de informações, por meio da aba "Acessibilidade", existente nas "Configurações" dos diferentes aparelhos tecnológicos. No caso dos dispositivos móveis e tablets são permitidos ajustes para: Visão (VoiceOver; Zoom; Inverter Cores; Tons de Cinza; Discurso: Falar Seleção, Falar Conteúdo da Tela, Falar Texto Automático;Texto Maior; Texto em Negrito; Figuras nos Botões; Aumentar Contraste; Reduzir Movimento; Símbolos nos Seletores); Audição (Aparelhos Auditivos; Flash do LED para Alertas/somente iPhone; Áudio Mono; Cancelamento de Ruído); Mídia (Legendas e legendas opcionais; Assinaturas de vídeo; Aprendizado; Acesso Guiado); Interação (Controle Assistivo; AssistiveTouch; Áudio das Ligações; Velocidade do clique em Início; Alcançabilidade -somente iPhone 6 e iPhone 6 Plus).

Em relação aos computadores e notebooks, além da "configuração" para "acessibilidade", disponível nos próprios sistemas (Windows, Linux, entre outros), há também softwares de código aberto como os leitores de tela que oferecem acessibilidade a partir de um sintetizador de voz (NVA, DOSVOX, JAWS, VIRTUAL VISION, etc.).

Essas configurações de acessibilidade promovem meios não somente para a inserção deste público no ambiente educacional; como também desencadeiam o que anteriormente foi mencionado como acessibilidade pedagógica.

Em síntese, o objetivo desse trabalho foi apresentar o ACESSAbilidade como um recurso público e acessível capaz de promover ações contínuas que possibilitem a inclusão e a permanência no ensino superior de estudantes público alvo da Educação Especial, sendo desenvolvido na região de Presidente Prudente (SP).

\section{METODOLOGIA}

Diante das considerações postas e do objetivo pretendido, a metodologia seguida envolveu a confecção de uma pesquisa exploratória, que para Gil (1989, p. 45) tem a intenção de proporcionar uma visão panorâmica do tipo aproximativo relativo a um determinado assunto; tendo como produto final um maior esclarecimento do problema de pesquisa "passível de investigação por processos mais sistematizados". O estudo envolveu: levantamento na literatura sobre acessibilidade pedagógica; mapeamento dos estudantes com algum tipo de deficiência matriculados dentro do período 2016-17 em IES (públicas e privadas) da região de Presidente Prudente (SP); criação do recurso de Educomunicação denominado de ACESSAbilidade; postagens continuadas sobre o assunto em fóruns online, instagram, twiter, grupo no whatsapp e o acompanhamento das interações. Para avaliação do andamento do projeto foram confeccionados relatos e avaliação de acessos do público e/ou "curtidas", a cada uma das ferramentas mencionadas.

O mapeamento foi realizado através de consultas na seção de graduação, assistência social, página da prefeitura do município e de informações disponibilizadas no VIII Fórum Municipal da Pessoa com Deficiência, realizado pelo Conselho Municipal da Pessoal com Deficiência (CONDEF) de Presidente Prudente, ocorrido no dia 14 de novembro de 2017, no Centro Cultural Matarazzo, complexo integrante da Secretaria Municipal de Cultura da cidade.

A intenção de se produzir conteúdo educativo via digital afina-se com os ideários da Educomunicação, conceito teórico que propõe o acesso do conhecimento a todos, fundamentado em uma lógica aberta, criativa e dialógica, relacionando a educação com a comunicação, defende que todas as pessoas envolvidas na rede da informação são criadoras de cultura independentemente de seu papel no ambiente no qual faz parte (SARTORI; SOARES, 2015). 
Assim como em experiências anteriores a 2017 sobre as barreiras existentes para a inclusão no ensino superior (DUSSILEK; MOREIRA, 2017; CERQUEIRA; MOREIRA; DUSSILEK, 2017); neste aprendizado foi observado que embora os estudantes sejam adultos e possam se deslocar, ainda há muitos obstáculos físicos a serem transpostos: dos arquitetônicos, passando pelos financeiros, aos existentes nos trajetos da residência às IES. Estes dificultam o comparecimento ou mesmo a assiduidade dos estudantes público-alvo da Educação Especial em encontros presenciais, para discussão da acessibilidade pedagógica entre outras questões; apontando como solução para este agravo o uso de tecnologias de comunicação em rede.

O presente estudo fez parte de um projeto de extensão que se encerrou em 2017 e de um projeto de pesquisa protocolado no Comité de Ética da IES pública. Participaram: uma graduanda em fisioterapia, bacharel em Psicologia, bolsista do projeto e autora do presente trabalho aqui apresentado e que legitima as considerações levantadas por ser cega; um aluno formado na Licenciatura da Educação Física em março de 2017; mas que continuou participando das atividades, como voluntário e a orientadora que é do curso de Educação Física.

\section{RESULTADOS}

Existem evidências na literatura (MARIAN; FERRARI; SEKKEL, 2007; DUARTE, 2013;) que permitem compreender algumas características, que motivam e que desmotivam esses estudantes a seguirem e a concluírem seus estudos neste nível de ensino. Foram elencados como desmotivadores: ausência de material didático adequado às deficiências específicas, dificuldades em acompanhar determinadas disciplinas em função de algumas especificidades da deficiência ou em função de períodos de instabilidade de saúde e o dilema das instituições em relação à aprovação de alunos com deficiências muito graves que não conseguiram efetivamente acompanhar o curso. Já os elementos motivadores foram apontados: a família, os colegas, centros de apoio aos estudantes criados dentro das próprias faculdades, e outros relacionados à acessibilidade e mobilidade. Estes últimos mostram-se muito mais como iniciativas das próprias instituições do que programas oriundos ou subsidiados por políticas públicas, quer sejam federais estaduais ou municipais, merecendo maiores investigações articuladas entre as IES.

Por meio do mapeamento realizado entre 2016-17 faziam parte do ensino superior de Presidente Prudente vinte estudantes nas quatro IES da cidade (destes cinco em instituição pública), em cursos variados como Geografia, Pedagogia, Direito, Arquitetura, Fisioterapia, Educação Física, considerando que áreas com enfoque acadêmico mais teórico oferecem melhor absorção deste público. Durante o processo do mapeamento tomou-se contato com alguns elementos relevantes para a inclusão e permanência desses estudantes no ensino superior até a conclusão da graduação. Destacam-se: a eficaz comunicação entre as várias instâncias da IES, desde a repartição que tem como função a matrícula, à responsável pelo acolhimento ou assistência social, à coordenadoria pedagógica, à secção de engenharia entre outras, ressaltando que o ambiente universitário necessita de uma melhor sensibilização em especial quanto às barreiras atitudinais. Outro ponto relaciona-se ao aspecto financeiro, muitas vezes a assistência pode ocorrer tanto através do auxílio que uma bolsa possibilitando a permanência deste estudante, assim como pelo apoio familiar e o encaminhamento pedagógico que um(a) professor(a) pode ter, ao sensibilizar-se com a superação do aluno, investindo nas possibilidades e potencialidades desse discente. Um terceiro tópico refere-se à "Recusa" por ajuda por parte do aluno com deficiência, por vergonha, medo de discriminação ou de mostrar fragilidade, situação que representa um conflito e cuja resolução merece maiores aprofundamentos investigativos, que representa uma limitação desse estudo.

Em relação a proposta de interação digital por meio do ACESSAbilidade, o recurso tem colaborado com respostas a questões relativas as características e especificidades das pessoas com deficiência na graduação, a saber: como elas aprendem, o que as facilita em termos de 
tecnologia e adaptações, e a estar aberto a explicitação de suas sugestões pedagógicas para aprimorar a relação didática graduando EPAEE como os docente; sem constrangimento ou receio.

Assim, faz parte da acessibilidade pedagógica para estes estudantes: um notebook com leitor de tela; a disponibilização de material didático em pdf pelo professor; o desenvolvimento de aplicativos de GPS que facilitem seu trânsito pela cidade e pela universidade; a substituição de avaliações tradicionais por outros suportes alternativos como provas escritas por orais, o preparo de avaliações em libras com aplicativo de celular (Vlibras, Hand talk, Giulia, entre outros); sensibilização, atualização e formação para professores de nível superior; efetivação do que é direito tal como o oferecimento de alunos tutores; discussão sobre a acessibilidade das bases de dados acadêmicas disponibilizadas para os estudos de nível superior e a premência pelo domínio de competências informacionais, não somente em termos de pesquisa acadêmica, mas também para a utilização na vida diária. Somente o conhecimento de como realizar essa equiparação seja pela interação social ou por meio da tecnologia que as distâncias atitudinais serão transpostas dentro do paradigma da inclusão em todos os níveis de ensino.

\section{DISCUSSÃO}

Pensando na correlação dos resultados com a inclusão de estudantes com deficiência no ensino superior, a Lei no 13.146 (BRASIL, 2015, p. XX) ao mesmo em tempo que é esclarecedora pelo menos em discurso, quanto ao direito à educação das pessoas com deficiência, também intensifica a relevância da acessibilidade pedagógica, inclusive a comunicacional. Por meio dela, o artigo 28 remete ao Estado a incumbência do:

[...]aprimoramento dos sistemas educacionais, visando a garantir condições de acesso, permanência, participação e aprendizagem, por meio da oferta de serviços e de recursos de acessibilidade que eliminem as barreiras e promovam a inclusão plena.

A prescrição menciona recursos de acessibilidade e serviços que devem ser ofertados pelo Estado, de forma a permear a condução do processo de adesão em permanência, ou seja do ingresso destes alunos até a conclusão da graduação e todos os desafios atitudinais e de sensibilização que envolvem a inclusão desses estudantes.

A norma citada considera a "acessibilidade" como:

[...]possibilidade e condição de alcance para utilização, com segurança e autonomia, de espaços, mobiliários, equipamentos urbanos, edificações, transportes, informação e comunicação, inclusive seus sistemas e tecnologias, bem como de outros serviços e instalações abertos ao público, de uso público ou privados de uso coletivo, tanto na zona urbana como na rural, por pessoa com deficiência ou com mobilidade reduzida. (Lei 13.146 (BRASIL, 2015, p. V).

Pelo exposto, entende-se que a acessibilidade não é somente o acesso físico aos espaços, prédios, mobiliários, transportes e aos componentes da urbanização existente, e sim um conceito mais amplo, que envolve a informação e o possível estabelecimento de redes comunicacionais, que incluem tecnologia, serviços variados, pontos de encontro virtuais e instalações físicas onde possam haver tanto interações presenciais como por meio de tecnologia, o que reforça a continuidade de disposição da ferramenta ACESSAbilidade.

\section{CONCLUSÃO}

A partir desse estudo, observou-se que a inclusão de pessoas com deficiência no ensino superior é recente, sendo necessário que as IES reflitam a respeito de suas estratégias e da acessibilidade pedagógica que oferecem, mesmo que o montante desse público ingresso no ensino superior ainda seja pequeno. Embora direito, nem sempre este é tratado como tal. 
É interessante uma sistematização de dados sobre os estudantes, seus cursos e as grandes áreas a que estes cursos pertencem, quais tecnologias utilizam (computador, celular) e modelos, além de outras informações necessárias, de forma articulada entre as instituições de ensino, para melhoria das interações entre eles e a compreensão das variáveis que estão direta e indiretamente envolvidas no processo do ingresso, adesão ao curso, permanência até a conclusão da graduação ou mesmo a evasão desses estudantes no município.

Quanto a iniciativa do ACESSAbilidade, ela teve visibilidade nas redes sociais e em eventos acadêmicos, o que reverteu para a bolsista, em um convite para ser palestrante no VIII Fórum Municipal da Pessoa com Deficiência, que somente ocorre de dois em dois anos, tendo como responsável pelo evento o CONDEF de Presidente Prudente.

\section{REFERÊNCIAS}

ACESSAbilidade. Rede Social voltada à interação de estudantes com deficiência. 2016. Disponível em:< https://www.facebook.com/acessabilidade/>. Acesso em 17 ago. 2018.

BRASIL. Lei no 13.146, de 6 de julho de 2015. Institui a Lei Brasileira de Inclusão da Pessoa com Deficiência (Estatuto da Pessoa com Deficiência). Disponível em:< http://www.planalto.gov.br/ccivil_03/_ato2015-2018/2015/lei/l13146.htm>. Acesso em 17 ago. 2018.

CERQUEIRA, M.R.R.; MOREIRA, J.C.C.; DUSSILEK, C. O ACESSABILIDADE como recurso educacional de interação digital: um relato de vivências em pesquisas realizadas em bases de dados online. 2017. Disponível em: <http://webcache.googleusercontent.com/search?q=cache:yjoqMUOj2zlJ:prope.unesp.br/cic/ad min/ver_resumo.php\%3Farea\%3D100091\%26subarea\%3D28702\%26congresso\%3D39\%26CPF\%3D $32133597859+\& c d=1 \& h|=p t-B R \& c t=c| n k \& g l=b r>$. Acesso em 17 ago. 2018

DUARTE, E. R. et al. Estudo de caso sobre a inclusão de alunos com deficiência no Ensino Superior. Rev. bras. Educação Especial, Marília, v.19, n.2, p.289-300, 2013 Disponível em:<http://www.scielo.br/scielo.php?script=sci_arttext\&pid=S141365382013000200011\&lng=en \&nrm=iso >. Acesso em 15 abril. 2015.

DUSSILEK, C.; MOREIRA, J.C.C. Inclusão no ensino superior: uma revisão sistemática das condições apresentadas aos estudantes com deficiência. 2017. Disponível em: <https://rsd.unifei.edu.br/index.php/rsd/article/view/124/141>. Acesso em 17 ago. 2018

GIL, A.C. Métodos e Técnicas da Pesquisa Social. São Paulo: Atlas, 1989. Disponível em:< https://ayanrafael.files.wordpress.com/2011/08/gil-a-c-mc3a9todos-e-tc3a9cnicas-de-pesquisasocial-1989.pdf>. Acesso em 17 ago.2018.

MARIAN, A. L.; FERRARI, D.; SEKKEL, M. C. Educação inclusiva no ensino superior: um novo desafio. Psicologia Ciência e Profissão, v. 27, n. 4, p. 636-647, 2007. https://doi.org/10.1590/S1414$\underline{98932007000400006}$

SARTORI, A. S.; SOARES, M. S. P. Concepção dialógica e as NTICs: a educomunicação e os ecossistemas comunicativos. $2005 . \quad$ Disponível em:< http://www.usp.br/nce/wcp/arq/textos/86.pdf>. Acesso em 17 ago. 2018. 
SASSAKI, R. K. Inclusão: acessibilidade no lazer, trabalho e educação. Revista Nacional de Reabilitação (Reação), São Paulo, a.XII, mar./abr. 2009, p. 10-16. Disponível em: <https://acessibilidade.ufg.br/up/211/o/SASSAKI_-_Acessibilidade.pdf?1473203319. Acesso em 07 mar. 2017. 